\title{
Prevalence of Sarcopenia Hospitalized Elderly Patients
}

\author{
Sanad HT; Ali SH; Alsadany MA; El Banouby MH
}

1 Geriatric Medicine \& Gerontology department, Faculty of Medicine, Ain Shams University, Cairo, Egypt.

\begin{abstract}
Background: Sarcopenia is a common clinical condition among elderly population. Sarcopenia is characterized by progressive generalized loss of skeletal muscle mass and strength with an increased risk of adverse outcomes as physical disability, poor quality of life, and death.

Aim: To evaluate prevalence of sarcopenia in hospitalized elderly patients.

Methods: A cross sectional study, included 127 elderly participants, men and women, 60 years old and above, who were admitted to geriatric department in Ain Shams University Hospital (El-Demerdash). Sarcopenia was defined according to EWGSOP criteria (European Working Groups on Sarcopenia in Older People) as low skeletal mass with either low hand grip strength or slow gait speed. Muscle mass was measured by bioelectrical impedance analysis $(B \mid A)$.
\end{abstract}

Results: Sarcopenia was found in $31 \%$ of all the study participants. Prevalence of sarcopenia was $47 \%$ among men and $14 \%$ among women. Sarcopenic participants had more functional decline and poor nutritional status. Malnutrition was present in $80 \%$ of sarcopenic men and $77 \%$ of sarcopenic women. Sarcopenia was associated with an increased risk of fall that was $90 \%$ among men and $88.9 \%$ among women. Elderly with sarcopenia had lower serum total protein and albumin levels.

Conclusions: Sarcopenia is highly prevalent among elderly Egyptian hospitalized patients. It is a hidden, although common, medical condition among elderly that can compromise their health, functional ability, and quality of life.

Keywords: sarcopenia, prevalence, hospitalized, elderly

\section{Background}

Sarcopenia is a common clinical condition among elderly population. It is a syndrome characterized by progressive and generalized loss of skeletal muscle mass, strength, and muscle function (Rosenberg, 1997). Sarcopenia had several definitions (Rosenberg, 1997) with no clear consensus on this issue. As a result, in 2010, the European Working Group on Sarcopenia in Older People (EWGSOP) developed consensus diagnostic criteria of age-related sarcopenia where sarcopenia was defined as a syndrome characterized by progressive and generalized loss of skeletal muscle mass and strength with an appreciated risk of adverse outcomes including physical disability, poor quality of life and death (Cruz-Jentoft et al., 2010).

Sarcopenia has multiple causes including diseases, decreased caloric intake, poor muscular blood flow, mitochondrial dysfunction, anabolic hormones deficiencies, and increase in pro-inflammatory cytokines (Morley et al., 2014).

Sarcopenia is a typical example of geriatric syndromes as it represents an impaired state of health with a high mobility disorders, impaired ability to perform 
activities of daily living, increased risk of falls and fractures, loss of independence and increased risk of death (Topinkova E, 2008).

In a systematic review, the prevalence of sarcopenia was between 1 and $29 \%$ in community-dwelling populations; $14-33 \%$ in long-term care populations. There is no much data concerning the incidence of sarcopenia among hospitalized elderly and the related risk factors. In a study done on hospitalized elderly patients, $25 \%$ of patients in a geriatric ward were found to be sarcopenic (Smoliner et al., 2014).

The aim of this study was to evaluate the incidence of sarcopenia in hospitalized elderly patients.

\section{Methods}

A cross sectional study was conducted. It included 127 elderly participants, 60 years old and above, both men and women, who were admitted to Ain Shams University Hospital (El-Demerdash). Participants were randomly selected. Those participants who had significant cognitive impairment (MMSE more than 24); delirium; advanced medical conditions; taking chemotherapy, steroids or statins were excluded.

Informed consent, either written or oral in case of illiteracy, was taken from each participant.

All individuals were subjected to comprehensive geriatric assessment that included a detailed medical history and physical examination.

\section{Assessment of sarcopenia:}

1) Measurement of muscle mass:

This was done by bioelectrical Impedance Analysis (BIA) using beurer Glass diagnostic scale (BG42, Germany). It measures the volume of fat and the lean body mass. It is inexpensive and easy to use. Under standard measurement techniques, its results correlate well with MRI results (Janssen et al., 2000).

The subjects stood over the scale after filling in data as age, height, gender, and level of activity (scored form a minimum of 1 and a maximum of 5). Absolute muscle mass was measured (not appendicular muscle mass) and total skeletal muscle mass index (TSMMI) was calculated. TSMMI = absolute muscle mass $/$ height in $\mathrm{m}^{2}$. The cut off points for muscle mass, which are based on a TSMMI, will be $<10.75 \mathrm{~kg} / \mathrm{m} 2$ for reduced muscle mass in men and $<6.75 \mathrm{~kg} / \mathrm{m} 2$ for reduced muscle mass in women (Janssen et al., 2000).

\section{2) Measurement of Muscle Strength:}

A handheld dynamometer (Jamar Hydraulic hand dynamometer; 5030J1, USA) was used to assess muscle strength.

Participants was instructed to keep their arms by the sides of their body. The participant squeezed the dynamometer with the dominant hand using maximum isometric effort. No other body movement was allowed and the better performance of the three trials were used (Roberts et al., 2001).

Low muscle strength was defined as hand grip strength less than $30 \mathrm{~kg}$ in men and $20 \mathrm{~kg}$ in women (Laurentani et al., 2003).

Physical performance:

Physical performance was assessed using usual gait speed. Each Participant was instructed to walk over a 10-m straight course at their usual speed. Usual gait speed will be derived from $4 \mathrm{~m}$ divided by the time in seconds spent in the middle $4 \mathrm{~m}$ (from the $4-\mathrm{m}$ line to the 8-m line). Good reproducibility of this measurement was reported previously. Usual gait speed values in the lowest quintile were classified as low physical performance. (cut-off values: $0.8 \mathrm{~m} / \mathrm{s}$ for both gender) (Laurentani et al., 2003).

Diagnosis is based on documentation of criterion 1 plus criterion 2 or criterion 3:

1- Low muscle mass

2- Low muscle strength

3- Low physical performance

(Cruz-Jentoft et al., 2010)

\section{Covariates}

Socio-demographic variables as age and gender were assessed. Participants were assessed for cognitive impairment by MMSE according to age and years of education (Folstein et al., 1975). Depression was assessed by PHQ2 score of equal or more than three (Spitzer et al., 1999). Functional assessment was done using ADL (Katz et al., 1963) and IADL (Lawton and Brody., 1969) depending on the participants' selfreported difficulty in performing different activities. The participant was declared dependent, assisted or independent according to their scores. Nutritional assessment was done using the MNA (mini nutritional assessment). The participants were classified, according to their score, into normal, at risk of malnutrition or malnourished (Vellas et al., 2006). Risk of fall was assessed by time up and go test (TUGT), 14 seconds or more is classified as at risk of fall (Podsiadlo and Richardson., 1991).

\section{Statistical Analysis}

Analysis of data was performed by using the Statistical Package for Social Science (SPSS16).

Description of all data in the form of mean (M) and standard deviation (SD) for all quantitative variables was done. Frequency and percentage was done for all qualitative variables. Comparison between quantitative variables was done using t-test to compare two groups. Comparison of qualitative variables was done using the Chi-square test or Fisher's exact test when appropriate. Significant level was measured according to $\mathrm{P}$ value (probability), $\mathrm{P}>0.05$ is insignificant, $\mathrm{P}<0.05$ is significant and $\mathrm{p}<0.01$ is highly significant.

\section{Results}

Table 1 shows that $47.6 \%$ of men participants were sarcopenic. Sarcopenic men had more functional decline with lower ADL and IADL scores, lower MNA 
Sanad HT et al. EJGG.2019; 6(1):22-30

Table 1: Geriatric domains and Lab. Assessment for men

\begin{tabular}{|c|c|c|c|c|c|}
\hline \multicolumn{3}{|c|}{ Men Participants $(n=65)$} & $\begin{array}{l}\text { Sarcopenic } \\
(n=31)\end{array}$ & $\begin{array}{l}\text { Not- } \\
\text { sarcopenic } \\
(n=34)\end{array}$ & P-Value \\
\hline \multicolumn{3}{|c|}{ Age in years $\quad($ Mean \pm SD $)$} & $70.23 \pm 6.37$ & $62.03 \pm 3.01$ & $<0.001$ \\
\hline \multicolumn{3}{|c|}{ Depressed by screening (PHQ2) } & $5(16.1 \%)$ & $3(8.8 \%)$ & 0.463 \\
\hline \multicolumn{3}{|c|}{ ADL (Activity of daily living) } & $13(41.9 \%)$ & $32(94.1 \%)$ & \multirow[t]{3}{*}{$<0.001$} \\
\hline & & Assisted (N \%) & $15(48.4 \%)$ & $2(5.9 \%)$ & \\
\hline & & Dependant (N \%) & $3(9.7 \%)$ & $0(0.0 \%)$ & \\
\hline \multirow{2}{*}{\multicolumn{3}{|c|}{$\begin{array}{l}\text { IADL (Instrumental activity } \\
\text { of daily living) }\end{array}$}} & $12(38.7 \%)$ & $32(94.1 \%)$ & \multirow[t]{3}{*}{$<0.001$} \\
\hline & & & $2(6.5 \%)$ & $2(5.9 \%)$ & \\
\hline \multicolumn{3}{|c|}{ Dependant (N \%) } & $17(54.8 \%)$ & $0(0.0 \%)$ & \\
\hline \multicolumn{3}{|c|}{ MNA score $($ Mean \pm SD) } & $9.81 \pm 2.06$ & $13.41 \pm 0.74$ & $<0.001$ \\
\hline \multirow{2}{*}{\multicolumn{3}{|c|}{$\begin{array}{l}\text { Nutritional status } \\
\text { according to MNA }\end{array}$}} & $6(19.4 \%)$ & $33(97.1 \%)$ & \multirow{3}{*}{$<0.001$} \\
\hline & & & $22(71.0 \%)$ & $1(2.9 \%)$ & \\
\hline & Mal-n & ition $\quad(\mathrm{N} \%)$ & $3(9.7 \%)$ & $0(0.0 \%)$ & \\
\hline \multicolumn{3}{|l|}{ TUG score (in seconds) } & $24.00 \pm 9.89$ & $12.32 \pm 6.70$ & $<0.001$ \\
\hline \multirow{2}{*}{\multicolumn{3}{|c|}{$\begin{array}{l}\text { Fall risk } \\
\text { (as per TUG test) }\end{array}$}} & $28(90.3 \%)$ & $11(32.4 \%)$ & \multirow[b]{2}{*}{$<0.001$} \\
\hline & & & $3(9.7 \%)$ & $23(67.6 \%)$ & \\
\hline \multicolumn{3}{|c|}{ Hemoglobin $($ gm/dl $) \quad($ Mean \pm SD $)$} & $11.97 \pm 1.49$ & $12.71 \pm 0.91$ & 0.018 \\
\hline \multicolumn{3}{|c|}{ Blood urea nitrogen $(\mathrm{mg} / \mathrm{dl}) \quad($ Mean $\pm \mathrm{SD})$} & $19.06 \pm 3.95$ & $21.47 \pm 9.40$ & 0.179 \\
\hline \multicolumn{3}{|c|}{ Creatinine $(\mathrm{mg} / \mathrm{dl}) \quad($ Mean \pm SD $)$} & $0.96 \pm 0.31$ & $0.78 \pm 0.18$ & 0.005 \\
\hline \multicolumn{3}{|c|}{ Total protein $(\mathrm{gm} / \mathrm{dl}) \quad($ Mean $\pm \mathrm{SD})$} & $5.05 \pm 0.46$ & $5.75 \pm 0.22$ & $<0.001$ \\
\hline \multicolumn{3}{|c|}{ Serum albumin $(\mathrm{gm} / \mathrm{dl}) \quad($ Mean $\pm \mathrm{SD})$} & $3.05 \pm 0.36$ & $3.84 \pm 0.19$ & $<0.001$ \\
\hline \multirow{8}{*}{\multicolumn{2}{|c|}{ Co-Morbidities }} & $\begin{array}{l}\text { Chest (COPD / Asthma / } \\
\text { IPF) }\end{array}$ & $10(32.3 \%)$ & $10(29.4 \%)$ & 0.608 \\
\hline & & Diabetes mellitus & $20(64.5 \%)$ & $28(82.4 \%)$ & 0.102 \\
\hline & & Cardiac disease & $5(16.1 \%)$ & $3(8.8 \%)$ & 0.463 \\
\hline & & Chronic kidney disease & $2(6.5 \%)$ & $2(5.9 \%)$ & 1.00 \\
\hline & & Anemia & $5(16.1 \%)$ & $0(0.0 \%)$ & 0.021 \\
\hline & & Hypertension & $22(71.0 \%)$ & $24(70.6 \%)$ & 0.973 \\
\hline & & Osteoarthritis & $22(71.0 \%)$ & $24(70.6 \%)$ & 1.00 \\
\hline & & Chronic liver disease & $14(45.2 \%)$ & $3(8.8 \%)$ & 0.001 \\
\hline \multicolumn{3}{|c|}{ Number of comorbidities (Mean \pm SD) } & $2.74 \pm 1.55$ & $2.21 \pm 1.23$ & 0.125 \\
\hline \multicolumn{3}{|c|}{ Charlson Comorbidity index } & $2.77 \pm 1.59$ & $2.26 \pm 1.40$ & 0.174 \\
\hline
\end{tabular}


Table 2: Geriatric domains and Lab. Assessment for women

\begin{tabular}{|c|c|c|c|c|}
\hline \multicolumn{2}{|c|}{ Women Participants $(n=62$} & $\begin{array}{l}\text { Sarcopenic } \\
\quad(n=9)\end{array}$ & $\begin{array}{c}\text { Not- } \\
\text { sarcopenic } \\
(n=53)\end{array}$ & P-Value \\
\hline \multirow{2}{*}{\multicolumn{2}{|c|}{ Age in years $\quad($ Mean \pm SD $)$}} & $68.22 \pm 7.50$ & $63.81 \pm 3.56$ & \\
\hline & & & & 0.119 \\
\hline \multicolumn{2}{|c|}{ Depressed by screening (PHQ2) } & $4(44.4 \%)$ & $3(5.7 \%)$ & 0.006 \\
\hline \multirow{2}{*}{\multicolumn{2}{|c|}{$\begin{array}{l}\text { ADL (Activity of daily } \\
\text { living) }\end{array}$}} & $2(22.2 \%)$ & $41(77.4 \%)$ & \multirow[t]{3}{*}{0.001} \\
\hline & & $6(66.7 \%)$ & $12(22.6 \%)$ & \\
\hline & Dependent (N \%) & $1(11.1 \%)$ & $0(0.0 \%)$ & \\
\hline \multirow{2}{*}{\multicolumn{2}{|c|}{$\begin{array}{l}\text { IADL (Instrumental } \\
\text { activity of daily living) }\end{array}$}} & $1(11.1 \%)$ & $39(73.6 \%)$ & \multirow[t]{3}{*}{$<0.001$} \\
\hline & & $0(0.0 \%)$ & $5(9.4 \%)$ & \\
\hline 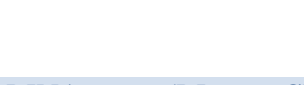 & $\begin{array}{c}\text { Dependent } \\
\%)\end{array}$ & $8(88.9 \%)$ & $9(17.0 \%)$ & \\
\hline \multicolumn{2}{|c|}{ MNA score (Mean \pm SD) } & $8.78 \pm 2.05$ & $12.49 \pm 1.28$ & $<0.001$ \\
\hline \multirow{3}{*}{$\begin{array}{l}\text { Nutritional status } \\
\text { according to } \\
\text { MNA }\end{array}$} & Normal $\quad(\mathrm{N} \%)$ & $2(22.2 \%)$ & $39(73.6 \%)$ & \multirow{3}{*}{$<0.001$} \\
\hline & $\begin{array}{l}\text { At risk of mal-nutrition } \\
(\mathrm{N} \%)\end{array}$ & $4(44.4 \%)$ & $14(26.4 \%)$ & \\
\hline & Mal-nutrition (N \%) & $3(33.3 \%)$ & $0(0.0 \%)$ & \\
\hline \multicolumn{2}{|l|}{ TUG score (in seconds) } & $25.67 \pm 8.93$ & $20.09 \pm 10.12$ & 0.126 \\
\hline \multirow{2}{*}{$\begin{array}{l}\text { Fall risk } \\
\text { (as per TUG test) }\end{array}$} & At risk of fall (N \%) & $8(88.9 \%)$ & $42(79.2 \%)$ & \multirow[b]{2}{*}{0.675} \\
\hline & Not at risk of fall $(\mathrm{N} \%)$ & $1(11.1 \%)$ & $11(20.8 \%)$ & \\
\hline \multicolumn{2}{|c|}{ Hemoglobin $(\mathrm{gm} / \mathrm{dl}) \quad($ Mean \pm SD $)$} & $11.94 \pm 1.78$ & $11.62 \pm 1.46$ & 0.556 \\
\hline \multicolumn{2}{|c|}{ Blood urea nitrogen $(\mathrm{mg} / \mathrm{dl}) \quad($ Mean \pm SD) } & $18.67 \pm 4.56$ & $19.91 \pm 5.04$ & 0.493 \\
\hline \multicolumn{2}{|c|}{ Creatinine $(\mathrm{mg} / \mathrm{dl}) \quad($ Mean \pm SD $)$} & $0.90 \pm 0.28$ & $0.87 \pm 0.18$ & 0.714 \\
\hline \multicolumn{2}{|c|}{ Total protein $(\mathrm{gm} / \mathrm{dl}) \quad($ Mean \pm SD $)$} & $4.89 \pm 0.38$ & $5.59 \pm 0.29$ & $<0.001$ \\
\hline \multicolumn{2}{|c|}{ Serum albumin $(\mathrm{gm} / \mathrm{dl}) \quad($ Mean $\pm \mathrm{SD})$} & $3.07 \pm 0.38$ & $3.58 \pm 0.32$ & $<0.001$ \\
\hline \multirow[t]{8}{*}{ Co-Morbidities } & $\begin{array}{l}\text { Chest (COPD / } \\
\text { Asthma / IPF) }\end{array}$ & $2(22 \%)$ & $1(1 \%)$ & 0.053 \\
\hline & Diabetes mellitus & $7(77.8 \%)$ & $40(75.5 \%)$ & 1.00 \\
\hline & Cardiac disease & $3(33.3 \%)$ & $8(15.1 \%)$ & 0.191 \\
\hline & $\begin{array}{l}\text { Chronic kidney } \\
\text { disease }\end{array}$ & $0(0.0 \%)$ & $2(3.8 \%)$ & 1.00 \\
\hline & Anemia & $3(33.3 \%)$ & $6(11.3 \%)$ & 0.115 \\
\hline & Hypertension & $7(77.8 \%)$ & $24(45.3 \%)$ & 0.147 \\
\hline & Osteoarthritis & $2(22.2 \%)$ & $15(28.3 \%)$ & 1.00 \\
\hline & Chronic liver disease & $2(22.2 \%)$ & $12(22.6 \%)$ & 1.00 \\
\hline \multicolumn{2}{|c|}{ Number of comorbidities (Mean \pm SD) } & $3.11 \pm 1.27$ & $2.02 \pm 1.01$ & 0.005 \\
\hline \multicolumn{2}{|c|}{ Charlson Comorbidity index } & $2.78 \pm 1.48$ & $2.19 \pm 1.40$ & 0.252 \\
\hline
\end{tabular}


Sanad HT et al. EJGG.2019; 6(1):22-30

Table 3: Muscle assessment tools for men

\begin{tabular}{|c|c|c|c|c|}
\hline & Men Participants $(n=65)$ & $\begin{array}{l}\text { Sarcopenic } \\
\qquad(n=31)\end{array}$ & $\begin{array}{l}\text { Not-sarcopenic } \\
\qquad(n=34)\end{array}$ & P-Value \\
\hline Hand grip (Kg) & Mean \pm SD) & $20.32 \pm 8.06$ & $36.35 \pm 11.34$ & $<0.001$ \\
\hline \multirow[t]{2}{*}{ Hand grip cut off } & Sarcopenic $(N$ \%) & $28(90.3 \%)$ & $7(20.6 \%)$ & \multirow[t]{2}{*}{$<0.001$} \\
\hline & not sarcopenic $(\mathrm{N} \%)$ & $3(9.7 \%)$ & $27(79.4 \%)$ & \\
\hline \multicolumn{2}{|c|}{ Body mass index $(\mathrm{BMI})\left(\mathrm{Kg} / \mathrm{m}^{2}\right) \quad($ Mean $\pm \mathrm{SD})$} & $23.48 \pm 3.02$ & $27.72 \pm 4.45$ & 0.000 \\
\hline \multicolumn{2}{|c|}{ Bioelectrical impedance analysis (BIA) $($ Mean \pm SD) } & $8.50 \pm 1.08$ & $9.92 \pm 1.64$ & $<0.001$ \\
\hline \multirow[t]{2}{*}{ BIA cut off } & Sarcopenic $(N$ \%) & $31(100.0 \%)$ & $20(58.8 \%)$ & \multirow[t]{2}{*}{$<0.001$} \\
\hline & Not sarcopenic $\left(\begin{array}{ll}N & \%\end{array}\right)$ & $0(0.0 \%)$ & $14(41.2 \%)$ & \\
\hline Gait speed $(\mathrm{m} / \mathrm{sec})$ & $($ Mean \pm SD) & $0.44 \pm 0.21$ & $0.84 \pm 0.20$ & $<0.001$ \\
\hline \multirow[t]{2}{*}{ Gait speed cut off } & Sarcopenic (N \%) & $28(90.3 \%)$ & $6(17.6 \%)$ & \multirow[t]{2}{*}{$<0.001$} \\
\hline & Not sarcopenic ( $\mathrm{N} \%)$ & $3(9.7 \%)$ & $28(82.4 \%)$ & \\
\hline
\end{tabular}

Table 3: Muscle assessment tools for women

\begin{tabular}{|c|c|c|c|c|}
\hline \multicolumn{2}{|c|}{ Women participants $(n=62)$} & \multirow{2}{*}{$\begin{array}{l}\text { Sarcopenic } \\
\begin{aligned}(n=9) \\
12.78 \pm 3.63\end{aligned}\end{array}$} & $\begin{array}{l}\text { Not-sarcopenic }(n= \\
53)\end{array}$ & \multirow{2}{*}{$\begin{array}{r}\text { P-Value } \\
0.01\end{array}$} \\
\hline Hand grip $(\mathrm{Kg})$ & $($ Mean \pm SD) & & $18.36 \pm 6.13$ & \\
\hline \multirow[t]{2}{*}{ Hand grip cut off } & Sarcopenic $\quad(N \quad \%)$ & $8(88.9 \%)$ & $22(41.5 \%)$ & \multirow[t]{2}{*}{0.01} \\
\hline & not sarcopenic $\quad\left(\begin{array}{ll}N & \%\end{array}\right)$ & $1(11.1 \%)$ & $31(58.5 \%)$ & \\
\hline \multicolumn{2}{|c|}{ Body mass index $(\mathrm{BMI})\left(\mathrm{Kg} / \mathrm{m}^{2}\right) \quad($ Mean $\pm \mathrm{SD})$} & $25.43 \pm 5.36$ & $34.21 \pm 6.11$ & 0.000 \\
\hline \multicolumn{2}{|c|}{$\begin{array}{l}\text { Bioelectrical impedance analysis (BIA) } \\
(\text { Mean } \pm \text { SD) }\end{array}$} & $5.79 \pm 1.49$ & $9.39 \pm 1.44$ & $<0.001$ \\
\hline \multirow[t]{2}{*}{ BIA cut off } & Sarcopenic & $7(77.8 \%)$ & $0(0.0 \%)$ & \multirow[t]{2}{*}{$<0.001$} \\
\hline & Not sarcopenic $\quad(\mathrm{N} \%)$ & $2(22.2 \%)$ & $53(100.0 \%)$ & \\
\hline Gait speed $(\mathrm{m} / \mathrm{sec})$ & (Mean \pm SD) & $0.41 \pm 0.25$ & $0.55 \pm 0.22$ & 0.09 \\
\hline Gait speed cut off & Sarcopenic & $8(88.9 \%)$ & $46(86.8 \%)$ & 1.00 \\
\hline
\end{tabular}


scores with a higher risk of malnutrition, and higher scores in TUG test indicating higher risk of fall, Depression didn't show any statistically significant difference. Lab results showed that sarcopenic men were more anemic, had a higher createnine and lower total protein and albumin levels. Although number of comorbidities and comorbidity index were slightly higher in sarcopenic men, yet it had no statistical significance. Only anemia and chronic liver disease showed significance.

Table 2 shows that $14.2 \%$ of women participants were sarcopenic. Sarcopenic women had more functional decline with lower ADL and IADL scores, and had lower MNA scores with a higher risk of mal-nutrition. Women as well, recorded higher score in TUG test indicating a higher risk of fall though it wasn't statistically significant. Regarding lab results; total protein and serum albumin levels were significantly lower in sarcopenic women, while hemoglobin and serum creatinine levels showed no statistical significance difference. Numbers of comorbidities were higher in sarcopenic women, but comorbidity index showed no statistically significant difference.

The table 3 shows that, sarcopenic men recorded lesser hand grip, and lesser muscle mass with BIA and lesser gait speed. These differences were statistically significant. Table 4 shows that sarcopenic women recorded lesser hand grip, lesser muscle mass assessed with BIA. Although gait speed was lower in sarcopenic women, but this difference was not statistically significant.

\section{Discussion:}

Sarcopenia is an important and a highly prevalent health problem in older adults that has a high rate of negative health related outcomes. This study was conducted aiming to determine the prevalence of sarcopenia among hospitalized elderly patients in acute care setting.

Although participants in our study were gender matched, sarcopenia was found to be highly prevalent among men compared to women $(47 \%$ in men versus $14 \%$ in women). This finding was consistent with similar results from other studies as (Pongchaiyakul et al., 2013), (Lim et al., 2011) and (Landi et al., 2011). This finding was explained by Gallagher and Delegge, (2011) who stated that men are likely to have higher prevalence of sarcopenia than women because of their higher rate of muscular atrophy than in women. On the contrary, other studies showed different findings as (Liu et al., 2014), (Cruz et al., 2010) and (Janssen et al., 2002) who stated that female gender was regarded as a risk factor for sarcopenia and a higher prevalence has been reported among women.

Our study showed that sarcopenia is highly prevalent among elderly hospitalized patients as $31 \%$ of the total participants were found to be sarcopenic.

The increasing prevalence of sarcopenia along with aging is similar to that was found in the iISIRENTE study (Landi et al, 2013).

With aging, decline occurs in many physiological systems by a rate of $2 \%$ per year which lead to significant muscle loss (Grune et al., 2001). In healthy young adults, skeletal muscle protein synthesis and degradation is a balanced, dynamic process with no net change occurring in skeletal muscle mass (Volpi et al., 2001). On the other side, during aging, muscle tissue loss occurs gradually, resulting in diminished mass and strength, a condition referred to as sarcopenia (Rosenberg., 1997)

In this study, the overall comorbidity index was similar with no statistically significant difference between sarcopenic and non-sarcopenic participants. However, cardiovascular diseases, anemia and chronic liver diseases were more common among sarcopenic compared to non-sarcopenic participants. That was consistent with Landi et al., (2011) who found an increased risk of sarcopenia among males affected by presence of certain chronic diseases as Parkinson's disease, chronic obstructive pulmonary disease, cerebrovascular disease and osteoarthritis.

Studying the geriatric domains among our study participants revealed that depression was more common among sarcopenic participants. Among men participants, depression was found more prevalent, although statistically non-significant, among sarcopenic men compared to non-sarcopenic (16\% versus $8 \%)$. While among women participants; $44 \%$ of sarcopenic participants were found depressed compared to only $5 \%$ in non-sarcopenic women. This finding agrees with Chang et al., (2017) who found a positive association between sarcopenia and depression, even when controlling other factors as BMI, gender, age, and other medical comorbidities.

Depression is associated with several factors such as female gender, living alone, low income and education levels, poor social support, and disability on daily work (Lapid \& Rummans., 2003; Tiemeier., 2003).

Yesavage et al., (1993) reported that physical illness, malnutrition, and poly-pharmacy were also among the factors that triggered depression. Same factors can precipitate sarcopenia as well. Also, Chang et al., (2017) have reported a positive association between sarcopenia and depression in their review. Similarly, many studies have shown that depressive disorders were associated with sarcopenia (Hsu et al., 2014; Kim et al., 2011)

We found that sarcopenia was associated with functional disabilities among our participants. Both men and women had low scores in their ADL and IADL. That was similar to the findings of a cohart study that showed association between sarcopenia and functional decline over a 2-year period follow up for 
elderly Japanese (Tanimoto et al., 2013). More studies also revealed similar results as (Yalcin et al., 2016) and (Velázquez et al., 2013).

Our study showed that sarcopenics are at increased risk of falling regardless of age, gender and other confounding factors. We used TUGT to assess the risk of fall. $90 \%$ of sarcopenic men were found to be at risk of fall, and this was nearly equal in sarcopenic women as $88.9 \%$ of them were at risk of fall.

Several observational studies have reported that reduced muscle strength, especially of the lower limbs is a major risk factor for falls (Blain et al., 2010), (Muscaritoli et al., 2010), (Visser et al., 2011).

In a systematic review and meta-analysis, lower extremity weakness was found as a clinically significant risk factor for falls, although this association was stronger in institutionalized compared to community-dwelling adults (Moreland et al., 2004). On the other side, the fall risk gets lower as the level of physical activity increases. This may be explained by the beneficial effect of physical activity on improving balance, co-ordination, muscle strength and reaction time (Hoekstra et al.,2011), (Breedveld et al.,2012).

Malnutrition and malnutrition risk were more frequent in our participants with sarcopenia. Malnutrition or risk of malnutrition were found in $80 \%$ of sarcopenic men compared to $77 \%$ of sarcopenic women. This is supported by a Mexican cohort study, who found high prevalence of sarcopenia among malnourished elderly women, although this study included communitydwelling participants (Velázquez et al., 2013). While, Bahat et al., (2010) reported that sarcopenia was related to poor nutritional status in Turkish older men who were living in a nursing home.

Low nutrient intake especially low protein intake strongly contributes with sarcopenia. Food intake declines with aging by $25 \%$ between the ages of 40 and 70. Such decline along with decreased appetite leads to 'anorexia of aging' which represents one of the causative factors for both malnutrition and sarcopenia (Sayer et al., 2013).

The current study showed that sarcopenics had lower albumin and total protiens serum levels compared to non sarcopenics. As sufficient amino acid and energy intake is crucial for muscle protein synthesis, it is possible that nutritional status contributes to the development of sarcopenia (Welch., 2014). So, implementing an efficient screening tools and improving nutritional status in older adults might give a good opportunity for management and early intervention for sarcopenia.

We found that hand grip was lower in sarcopenic men $(20 \pm 8 \mathrm{~kg})$ compared to non-sarcopenic men $(36 \pm 11$ $\mathrm{kg})$. Similarly, sarcopenic women recorded a lower hand grip values $(12 \pm 3 \mathrm{~kg})$ compared to nonsarcopenic women $(18 \pm 6 \mathrm{~kg})$. These findings were consistent with similar findings from many other studies (Samuel et al., 2012) and (Roberts et al., 2011). Grip strength was considered as a good indicator of upper limb performance in everyday activities (Desrosiers et al., 1995), while, Hunter et al., (1998) suggest that strength of a specific muscle group might not be indicative of musculoskeletal function of all the muscles of an individual.

Gait speed was used as a marker of physical performance. Gait speed was lower is sarcopenic men $(0.44 \pm 0.21 \mathrm{~m} / \mathrm{sec})$ compared to non-sarcopenic men $(0.84 \pm 0.2 \mathrm{~m} / \mathrm{sec})$. sarcopenic women as well showed to have lesser gait speed. They recorded $(0.41 \pm 0.25$ $\mathrm{m} / \mathrm{sec})$ compared to $(0.55 \pm 0.22 \mathrm{~m} / \mathrm{sec})$ among nonsarcopenic women. That was consistent with findings from other studies such as (Cesari et al., 2005), (CruzJentoft et al., 2010), and (Morley et al., 2011). Such studies correlated the deterioration of gait speed and physical performance to the age-related muscle changes that occurs with aging (Ferrucci et al., 1999) and even accelerated with chronic inflammatory conditions (Cesari et al., 2004).

It is concluded that sarcopenia is highly prevalent in elderly within acute care setting. Some factors may be tackled like mood and nutritional status to hinder and consequently avoid sequel like functional decline.

In elderly patients, we may need to do interventional studies to see effect of nutritional support and depression management on sarcopenia parameters.

Limitations: the study was limited by its narrow sample size and its exclusion criteria.

\section{References}

1. Bahat, G., Saka, B., Tufan, F., et al., (2010): Prevalence of sarcopenia and its association with functional and nutritional status among male residents in a nursing home in Turkey. The Aging Male, 13(3), 211-214.

2. Blain, H., Carriere, I., Sourial, et al., (2010): Balance and walking speed predict subsequent 8-year mortality independently of current and intermediate events in well-functioning women aged 75 years and older. The journal of nutrition, health \& aging, 14(7), 595-600.

3. Breedveld-Peters, J. J., Reijven, P. L., Wyers, C. E., et al., (2012): Integrated nutritional intervention in the elderly after hip fracture. A process evaluation. Clinical nutrition, 31(2), 199-205.

4. Cesari, M., Kritchevsky, S. B., Penninx, B. W., et al., (2005): Prognostic value of usual gait speed in well-functioning older people-results from the health, aging and body composition study. Journal of the American Geriatrics Society, 53(10), 1675-1680.

5. Cesari, M., Penninx, B. W., Pahor, M., et al., (2004): Inflammatory markers and physical performance in older persons: the InCHIANTI study. The Journals of Gerontology Series A: Biological Sciences and Medical Sciences, 59(3), M242-M248.

6. Chang, K. V., Hsu, T. H., Wu, W. T., et al., (2017): Is sarcopenia associated with depression? A systematic review and meta-analysis of observational studies. Age and ageing, 46(5), 738-746.

7. Cruz-Jentoft AJ, Baeyens JP, Bauer JM, et al., (2010): Sarcopenia: European consensus on definition and diagnosis: Report of the European Working Group on Sarcopenia in Older People, 39(4):412-423. 
8. Cruz-Jentoft, A. J., Landi, F., Topinkova, E., et al., (2010): Understanding sarcopenia as a geriatric syndrome. Current Opinion in Clinical Nutrition \& Metabolic Care, 13(1), 1-7.

9. Desrosiers, J., Bravo, G., Hebert, R., et al (1995): Normative data for grip strength of elderly men and women. American Journal of Occupational Therapy, 49(7), 637-644

10. Ferrucci, L., Harris, T. B., Guralnik, J. M., et al., (1999): Serum IL-6 level and the development of disability in older persons. Journal of the American Geriatrics Society, 47(6), 639-646.

11. Folstein MF, Folstein SE, and McHugh PR (1975): Mini Mental State: a practical method for grading the cognitive state of patients for the clinician. J Psychiatr Res; 12:189-198.

12. Gallagher, D., \& DeLegge, M. (2011): Body composition (sarcopenia) in obese patients: implications for care in the intensive care unit. Journal of Parenteral and Enteral Nutrition, 35(5_suppl), 21S-28S

13. Grune, T., Shringarpure, R., Sitte, N., et al., (2001): Age-related changes in protein oxidation and proteolysis in mammalian cells. The Journals of Gerontology Series A: Biological Sciences and Medical Sciences, 56(11), B459-B467.

14. Hoekstra, J. C., Goosen, J. H., de Wolf, G. S., et al., (2011): Effectiveness of multidisciplinary nutritional care on nutritional intake, nutritional status and quality of life in patients with hip fractures: a controlled prospective cohort study. Clinical nutrition, 30(4), 455461.

15. Hunter, S., White, M., \& Thompson, M. (1998): Techniques to evaluate elderly human muscle function: a physiological basis. The Journals of Gerontology Series A: Biological Sciences and Medical Sciences, 53(3), B204-B216.

16. Janssen, I., Heymsfield, S. B., \& Ross, R. (2002): Low relative skeletal muscle mass (sarcopenia) in older persons is associated with functional impairment and physical disability. Journal of the American Geriatrics Society, 50(5), 889-896.

17. Janssen, I., Heymsfield, S.B., Baumgartner, R.N. et al., (2000): Estimation of skeletal muscle mass by bioelectrical impedance analysis. Journal of applied physiology, 89(2), pp.465-471.

18. Katz S, Ford AB, Moskowitz RW, et al., (1963): Studies of illness in the aged: The index of ADL: A standardized measure of biological and psychosocial function. JAMA, 185(12), 914-919.

19. Landi, F., Cruz-Jentoft, A. J., Liperoti, R., et al (2013): Sarcopenia and mortality risk in frail older persons aged 80 years and older: results from ilSIRENTE study. Age and ageing, 42(2), 203-209.

20. Landi, F., Liperoti, R., Fusco, D., et al., (2011): Prevalence and risk factors of sarcopenia among nursing home older residents. Journals of Gerontology Series A: Biomedical Sciences and Medical Sciences, 67(1), 48-55.

21. Lauretani F1, Russo CR, Bandinelli $S$ et al., (2003): Age-associated changes in skeletal muscles and their effect on mobility: an operational diagnosis of sarcopenia. J Appl Physiol; 95(5):1851-60.

22. Lawton MP and Brody EM (1969): Assessment of older people: self-maintaining and instrumental activities of daily living. Gerontologist; 9 (3):179-186.

23. Lim, S., Kwon, S. Y., Yoon, et al., (2011): Association between body composition and pulmonary function in elderly people: the Korean Longitudinal Study on Health and Aging. Obesity, 19(3), 631-638.

24. Liu, L. K., Lee, W. J., Chen, L. Y., et al., (2014): Sarcopenia, and its association with cardiometabolic and functional characteristics in Taiwan: Results from I-Lan Longitudinal Aging Study. Geriatrics \& gerontology international, 14(S1), 36-45.

25. Moreland, J. D., Richardson, J. A., Goldsmith, C. H., et al., (2004): Muscle weakness and falls in older adults: a systematic review and meta-analysis. Journal of the American Geriatrics Society, 52(7), 1121-1129.

26. Morley, J. E., Abbatecola, A. M., Argiles, J. M., et al., (2011): Sarcopenia with limited mobility: an international consensus. Journal of the American Medical Directors Association, 12(6), 403-409.

27. Morley, J.E., Anker, S.D. and von Haehling, S., (2014): Prevalence, incidence, and clinical impact of sarcopenia: facts, numbers, and epidemiology-update 2014. Journal of cachexia, sarcopenia and muscle, 5(4), pp.253-259.

28. Muscaritoli, M., Anker, S. D., Argiles, J., et al., (2010): Consensus definition of sarcopenia, cachexia and precachexia: joint document elaborated by Special Interest Groups (SIG)"cachexia-anorexia in chronic wasting diseases" and "nutrition in geriatrics". Clinical nutrition, 29(2), 154-159.

29. Podsiadlo D and Richardson S (1991): "The timed 'Up \& Go': A test of basic functional mobility for frail elderly persons". Journal of the American Geriatrics Society. 39 (2): 142-148

30. Pongchaiyakul, C., Limpawattana, P., Kotruchin, P., et al., (2013): Prevalence of sarcopenia and associated factors among Thai population. Journal of bone and mineral metabolism, 31(3), 346-350.

31. Roberts, H. C., Denison, H. J., Martin, H. J., et al., (2011): A review of the measurement of grip strength in clinical and epidemiological studies: towards a standardised approach. Age and ageing, 40(4), 423 429.

32. Rosenberg, I.H., (1997): Sarcopenia: origins and clinical relevance. The Journal of nutrition, 127(5), pp.990S-991S.

33. Samuel, D., Wilson, K., Martin, H. J., et al., (2012): Age-associated changes in hand grip and quadriceps muscle strength ratios in healthy adults. Aging clinical and experimental research, 24(3), 245-250.

34. Sayer, A. A., Robinson, S. M., Patel, H. P., et al., (2013): New horizons in the pathogenesis, diagnosis and management of sarcopenia. Age and ageing, 42(2), 145-150.

35. Smoliner, C., Sieber, C.C. and Wirth, R., (2014) Prevalence of sarcopenia in geriatric hospitalized patients. Journal of the American Medical Directors Association, 15(4), pp.267-272.

36. Tanimoto, Y., Watanabe, M., Sun, W., et al., (2013): Association of sarcopenia with functional decline in community-dwelling elderly subjects in Japan. Geriatrics \& gerontology international, 13(4), 958-963.

37. Topinková, E., (2008): Aging, disability and frailty. Annals of Nutrition and Metabolism, 52(Suppl. 1), pp.611.

38. Velázquez Alva, M. D. C., Irigoyen Camacho, M. E., Delgadillo Velázquez, J., et al., (2013). The relationship between sarcopenia, undernutrition, physical mobility and basic activities of daily living in a group of elderly women of Mexico City. Nutricion hospitalaria, 28(2).

39. Vellas B, Villars H, Abellan G, et al., (2006): Overview of the MNA $®$ - Its History and Challenges. J Nutr Health Aging; 10 (6): 456-465

40. Visser, M., \& Schaap, L. A. (2011): Consequences of sarcopenia. Clinics in geriatric medicine, 27(3), 387 399.

41. Volpi, E., Sheffield-Moore, M., Rasmussen, B. B., et al., (2001): Basal muscle amino acid kinetics and protein synthesis in healthy young and older men. Jama, 286(10),

$1206-1212$ 
Sanad HT et al. EJGG.2019; 6(1):22-30

42. Welch, A. A. (2014): Nutritional influences on agerelated skeletal muscle loss. Proceedings of the Nutrition Society, 73(1), 16-33.

43. Yalcin, A., Aras, S., Atmis, V., et al., (2016): Sarcopenia prevalence and factors associated with sarcopenia in older people living in a nursing home in Ankara Turkey. Geriatrics \& gerontology international, 16(8), 903-910. 